\title{
An enlightened approach to legislative scrutiny: focusing on effectiveness
}

\author{
By Prof. Helen Xanthaki ${ }^{1}$
}

\section{A. Hypothesis and method}

Effectiveness is now widely embraced as a measure of legislative quality by international and national lawmakers, and academic and professional drafters. ${ }^{2}$ However, it continues to remain abstract as a form of wish or intent, rather than a concrete, applied concept. When it comes to legislative scrutiny, effectiveness remains in the aether but its concrete application to legislative scrutiny (which, after all, is a mechanism set to measure the possible or post facto success of legislation) remains untold. The aim of this paper is to find and express the concrete mechanism of application of the concept of legislative effectiveness to pre- and post-legislative scrutiny. Legislative scrutiny here is used as a generic term, encompassing Thornton's internal and external verification as the fifth stage of legislative drafting, evaluation ex ante via impact assessment or cost benefit analysis, and post legislative ad hoc or regular monitoring scrutiny exercises linked to sunset clauses or not.

The hypothesis of this paper is that the effective legislative scrutiny requires holistic and individualised analysis of the particular legislative text that cannot be restricted into formalistic, pre-prepared, universally applied criteria expressed in multiple-choice or box-ticking styled model forms. In this sense, the paper departs from the trend of model forms (be it Impact Assessments forms, cost benefit analysis forms, or legislative effectiveness forms). The paper proposes that, not in their stead but perhaps in an overview of the existing scrutiny mechanisms,

\footnotetext{
${ }^{1}$ Helen Xanthaki, LLB (Ath), MJur, PhD (Dunelm), SFHEA, is Professor of Law, UCL; Director of PGLaws Programmes, University of London; Senior Research Fellow, IALS; and President of the International Association for Legislation.

2 European Commission, 'European Governance: Better lawmaking' (Communication) COM (2002) 275 final; EP, Council, Commission, Interinstitutional Agreement on better law-making [2003] Official Journal of the European Union C C321/1, point 25, http://eurlex.europa.eu/LexUriServ/LexUriServ.do?uri=CELEX:32003Q1231\%2801\%29:EN:NOT; UK OPC, Drafting Guidance, 2017, https://www.gov.uk/government/uploads/system/uploads/attachment_data/file/666328/drafting_guidance_Dec 2017.pdf; Australian OPC, Reducing complexity in legislation, June 2016, http://www.opc.gov.au/about/docs/ReducingComplexity.pdf; Government of Canada, Guide to Making Federal Acts and Regulations, 2001, http://www.pco.gc.ca/docs/information/publications/legislation/pdf-eng.pdf.
} 
legislation is evaluated by means of individualised, concrete, measurable criteria that answer narratively a list of holistic questions focusing on pre- or post-legislative scrutiny.

In order to prove this hypothesis, the paper begins with the definition of effectiveness. It continues to place effectiveness within the realm of phronesis and phronetic legislative drafting, thus explaining and proving its inherent fluidity. It identifies the elements of an enlightened scrutiny exercise that takes into account the individuality and fluidity of effectiveness. And it proposes the use of a new genre of purpose/objectives clauses for the binding legislative expression of individualised criteria to be applied in the scrutiny of the particular text.

\section{B. Defining Effectiveness ${ }^{3}$}

It would be wrong to define effectiveness of legislation in a vacuum. From an instrumental functional perspective, legislation is one of the tools available to governments in their attempt to regulate behaviours in response to undesirable social phenomena. Governments come to power with a mandate: in democracies, the constituting elements of that mandate are agreed with the people during elections; in autocracies, the constituting elements of that mandate are decided by dictators and imposed on the people. Whichever way the mandate comes about, it sets out a list of policy aims that are attainable by means of regulatory reforms. These reforms can be achieved by a great variety of regulatory tools, ranging from flexible forms of traditional regulation (such as performance-based and incentive approaches), to co-regulation and selfregulation schemes, to incentive and market based instruments (such as tax breaks and tradable permits), to information approaches, and, last and least, to the traditional, overestimated and highly popular tool of legislation. In fact, alternative tools for regulation are a better choice for governments. After all, these are free from the many inherent limits of legislation, such as reliance on diverse regulatory agents, expression in a rigid unfriendly written communication, inherent aversion of citizens to legal texts, and a complicated interconnection with the other legislative texts in the labyrinth of the statute book.

\footnotetext{
${ }^{3}$ Helen Xanthaki, on Transferability of Legislative Solutions' in C. Stefanou and H. Xanthaki (Eds) Drafting Legislation. A Modern Approach (Ashgate 2008) 1-18, 17; H. Xanthaki, Drafting Legislation. Art and Technology of Rules for Regulation (2014) 7.
} 
Viewing legislation as a regulatory tool leads easily into the definition of a good law. A good law is simply one that is capable of contributing to the production of the desired regulatory results. ${ }^{4}$ Let us explore this further.

The ultimate goal for any regulation is efficacy, defined as the extent to which regulators achieve their goals. Efficacy is a rather factual quality, whose presence is easily established by means of measurable criteria. For example, if the aim of the regulation is to reduce the number of illegal abortions within a jurisdiction, efficacy is easily assessed by data setting the number of illegal abortions before and after the regulation was put to place. A reduction in the number of illegal abortions proves efficacy of regulation, whereas an increase or plateau in the numbers of illegal abortions points to inefficacy.

Of course, assessing efficacy is not such a simplistic task.

It requires an accurate identification of the policy aim behind regulatory aspirations. Were illegal abortions banned as a means of ending the suffering and possible death of the poor women who resort to them? Were they banned to curb the strain of their unintended consequences on the budget of the national health service, where injured victims end up after things go wrong? Were they banned because the aim of the country is to increase its population? Were they banned for ethical, cultural or religious reasons? Policy officers need to be aware of the link between regulation and the production of regulatory results, and they need to have identified the desired regulatory results before framing the regulation. This requires a reversal from the decision to legislate as a reaction to political pressure, which ignores the regulatory framework; and it requires the introduction of social policy study to understand how the results can be produced (namely what the roots of the problem are and what policy options can address it). In the example above, an efficacious regulatory mechanism to address the ban of illegal abortions for the protection of women's health, or for the safeguarding of the budget of the national health service could be the provision of contraception and the availability of legal abortions. Similarly, the efficacious response to cultural, ethical or religious objections is an information campaign, probably combined with easy access to alternatives. Finally, an efficacious response to the aspiration of growth of the population could be the introduction of financial benefits for large families. The example proves that the real policy aim of the legislation directly affects its regulatory efficacy.

\footnotetext{
${ }^{4}$ H. Xanthaki, 'Drafting Manuals and Quality in Legislation: Positive Contribution towards Certainty in the Law or Impediment to the Necessity for Dynamism of Rules' [2010] Legisprudence IV 2115
} 
Effectiveness is an even more complex concept to measure. Effectiveness is defined as the capacity of the legislative text to contribute to regulatory efficacy. This makes it intrinsically linked, and dependent upon, efficacy. Effectiveness measures the possible success of the expression of regulation in a legislative text. But the success of expression is only relevant if there is success in the content of the regulation. A wonderfully drafted law cannot possibly contribute to the production of the desired regulatory results, if the choice of regulatory mechanism is haphazard and consequently doomed to miss its target from the word go. For example, reducing the number of illegal abortions cannot be achieved if legal abortions or contraception are not a possible option for women; increasing the penalty for illegal abortions, even at nauseating criminal heights, will not work, irrespective of how well one drafts the relevant criminal provision.

Effectiveness has a further attribute of complexity. It is intrinsically linked to the environment to which the text is placed. Effectiveness reflects the extent to which the legislation manages to introduce adequate mechanisms capable of producing the desired regulatory results, at the specific jurisdictions and the specific time. Cultural, social, religious, legislative eccentricities of the jurisdiction affect effectiveness heavily. For example, the use of "shall" in UK legislation is ambiguous: it may mean a promise for the future ("will") or a very strong "must". In contrast, in most of Africa "shall" is a necessary legislative expression, as it has come to represent an undisputed legislative command. In that sense, effectiveness is individualised.

It is also fluid. Expressions that were acceptable in the past, are no longer so. Modern legislation maintaining the now unacceptable term "bastard children" in the UK would probably remain ineffective, as societal repulsion to the term would detach users from its detailed reading, consequent understanding, and subsequent implementation. Yet it was used rather frequently in old family law and succession Acts.

Despite its fluidity and relativity, effectiveness is a solid criterion of legislative quality. It applies to all types of legislative instruments. If the purpose of legislation is to serve as a symbol, then effectiveness becomes the measure of achieved inspiration of the users of the symbol legislation. If legislation is to be used as a ritual, effectiveness takes the robe of persuasion of the users who bow down to its appropriate rituality. If legislation is functional, effectiveness measures the extent of the production of the desired regulatory results. 
Effectiveness is nurtured by clarity, precision, and unambiguity. Clarity is the quality of being clear and easily perceived or understood. Precision is the exactness of expression or detail. Unambiguity is certain or exact meaning: semantic unambiguity requires a single meaning for each word used, whereas syntactic unambiguity requires clear sentence structure and correct placement of phrases or clauses. In turn, clarity is served by plain language. Plain language in its meta-modern guise of easified language requires the pitching of legislative communication to the level of linguistic and legal awareness of the audience of the specific legislative text. Similarly, precision and unambiguity are served by gender neutral language, namely the use of non-gender specific legislative expression where gender is not relevant.

There are two misconceptions that may arise from the definition and conceptual analysis of effectiveness. The first is that, since effectiveness is nurtured by linguistic choices, it only refers to words and syntax: legislative expression may be crucial in the manner in which concepts are communicated to the legislative audience but it is not exclusive to the task. The dependency of effectiveness to regulatory efficacy extends the field of effectiveness much wider: the soundness of regulatory goals; the appropriateness of regulatory choices; the suitability of legislation as a tool for the achievement of the policy goals; the accurate identification of the legislative audience; the clarity of an easified structure of the legislative text; and of course the clarity, precision and unambiguity of linguistic expression of the resulting easified legislative text. Such a wide concept requires an equally wide concept of scrutiny.

The question here is whether this wide, fluid and relative concept of effectiveness can become more concrete, thus delimiting the elements of its scrutiny to concrete factors.

\section{Effectiveness in the framework of phronetic legislative drafting}

In order to answer this question, effectiveness must be viewed within the framework in which it functions. If legislation itself is a rigid product, then its evaluation can also be rigid: effectiveness as a measure of legislative quality can then also present as rigid. If, however, legislation itself is fluid and relative, so is its qualitative criterion, effectiveness. 
The nature of legislation as a process and a product is phronetic. Phronesis ${ }^{5}$ is the praxis of subjective decision making on factual circumstances or the practical wisdom of the subjective classification of factual circumstances to principles and wisdom as episthmh. ${ }^{6}$ Phronesis is practical reasoning, practical wisdom, moral discernment, moral insight, and produce. ${ }^{7}$ Phronesis is "the art of judgement". ${ }^{8}$ According to Voegelin, phronesis differs from the dianoetic virtues of episteme-science that draws conclusions from principles; from nousintellect, which recognizes first principles; and from sophia-wisdom, which, as a combination of science and intellect, refers to things divine. ${ }^{9}$

Phronetic law is concerned with reflection about values and interests with reference to praxis based on practical value-rationality. ${ }^{10} \mathrm{Law}$ as phronesis encourages continued uniform application, and thus supports certainty and the rule of law in the civil law tradition. Law as phronesis supports prudence or appropriateness, and hence stare decisis, in the common law tradition. Phronesis can serve as a concrete guide to anyone wishing to ameliorate justice by urging the subject to answer the following questions: Where are we heading to? Who wins and who loses, and by virtue of what mechanisms? What are desirable consequences? What can be done on this topic ${ }^{11}$ Phronesis supports probabilistic reasoning, as opposed to deductive reasoning, which can be defined as the selection of solutions made on the basis of informed yet subjective application of principles on set circumstances. ${ }^{12}$ Phronesis is "practical wisdom that responds to nuance and a sense of the concrete, outstripping abstract or general theories of what is right. In this way, practical wisdom relies on a kind of immediate insight, rather than more formal inferential processes". ${ }^{13}$ Phronesis provides the means to achieve the purpose. ${ }^{14}$

Legislation is phronetic. It is a liberal discipline where theoretical principles guide the drafter to conscious decisions made in a series of subjective empirical and concrete choices. And, as it is phronetic, law is context dependent, in the sense that it can only inform on what

\footnotetext{
${ }^{5}$ Aristotle, Nichomachean Ethics, bk VI, chs. 5-11 (D. Ross trans. 1980).

${ }^{6}$ S-U von Kirchmann, Die Werlosigkeit der Jursprudenz als Wissenschaft (Berlin, Verlage von Julius Springer, 1848).

7 J. Noel, 'On the varieties of phronesis' (1999) 31 Educational Philosophy and Theory 273, 273.

${ }^{8}$ G. Vickers, The Art of Judgement: A Study of Policy Making (London, Sage, 1995).

${ }^{9}$ E. Voegelin, above, n 92; and also Aristotle, Nicomachean Ethics, above, n 86, 6.6-7.

${ }^{10}$ Drawn from Flyvnergs definition of planning as phronesis: B. Flyvbjerg, 2004, above,n 97, 287.

${ }^{11}$ M. Deschamps, 'L'acces a la justice, l' affaire de chacun' (2009) 50 Cahiers de Droit 248, 253.

12 E. Engle, 'Aristotle, Law and Justice: the tragic hero' (2008) 35 NKyLRev 1, 4.

${ }^{13}$ C. Rideout, 'Storytelling, narrative rationality, and legal persuasion'(2008) 14 Legal Writing: J Legal Writing Inst 53, 75 .

${ }^{14}$ J. Moss, 'Virtue Makes the Goal Righ: Virtue and Phronesis in Aristotle's Ethics' (2011) 56 Phronesis: A

Journal for Ancient Philosophy 204.
} 
might work in certain circumstances, but the decision about what to do in any specific circumstance will always depend on normative judgements that have to be made by those who are there ${ }^{15}$ It is also subject to revision as new perspectives are encountered: it is always revisable. ${ }^{16}$ And it supports particularity. ${ }^{17}$

And this lies at the heart of the nature of effectiveness as fluid and relative. ${ }^{18}$ Legislation is a phronetic creature. It is not ruled by the rigid laws of science: gravity will always work in nature, but the use of a drafting convention may well lead to different results in different jurisdictions and at varied times. The fluidity and relativity of legislation as a product invites its assessment by qualities that are equally flexible and fluid. Measuring legislative quality by the number of "shall" in its text may be tantalisingly convenient but it is useless in substance. Legislation can be effective when using "shall" in African criminal laws and equally ineffective in UK social care legislation.

The criterion of legislative quality requires a well-defined criterion that prevents its manipulation in order to produce correct measurements. The phonetic nature of legislation invites its measurement by means of a clear, precise and rigidly bordered unambiguous concept that, however, is flexible enough to encompass the fluidity and relativity of legislation. Effectiveness is indeed conceptually rigidly defined: it signifies the capacity of legislative texts to contribute to the achievement of the desired regulatory results. But its conceptual referents vary from text to text, as it takes into account the interdependence of legislation to legal and regulatory choices, and variations of legislative audiences not only within the same but also within varied political, cultural, religious, and linguistic environments.

\section{An enlightened exercise of legislative scrutiny}

An enlightened approach to legislative scrutiny uses effectiveness as the criterion of choice. Which, by definition, excludes pre-prepared rigid forms that can be easily ticked in useless formalistic box ticking exercises of impact assessment. Equally, it excludes strict focus on

\footnotetext{
${ }^{15}$ M. Griffiths and G. MacLeod, 'Personal Narratives and Policy: Never the Twain?', above, n 84, 129.

${ }^{16}$ H. Arendt, The Human Condition (London and Chicago, University of Chicago Press, 1958) 129.

${ }^{17}$ S. Schwarze, 'Performing Phronesis: The Case of Isocrates Helen' (1999) 32 Philosophy \& Rhetoric 78, 78.

${ }^{18} \mathrm{~W}$. Voermans, "Concern about the quality of EU legislation: what kind of problem, by what kind of standards?” [2009] Erasmus Law Review 66-68; U. Karpen, "Efficacy, Effectiveness, Efficiency: From Judicial to Managerial Rationality" in K. Messerschmidt and D. Oliver-Lalana, Rational Lawmaking under Review: Legislprudence according to the German Federal Constitutional Court (2016, Springer, Berlin), pp.303 ss.
} 
linguistic and stylistic drafting choices, as it extends to the whole regulatory cycle of which legislation is a part. And it invites inter-disciplinarity in its conceptualisation and conduct: it invites the contribution of policy officers, who can assess the extent of achievement of regulatory goals; finance officers who can measure cost efficiency; lawyers who can assess the effects of the legislation to the legal system as a whole; and drafters who can use all the above data, and assess the effectiveness of the text.

Mousmouti's effectiveness test proposes focus on objectives, content, context, and results ${ }^{19}$. Purpose tests the link between the purpose of the law and the policy objectives. Content tests the responsiveness of the legislative choices to the underlying social phenomenon, and the consistency and alignment between the choice of rules, enforcement mechanisms and communication. Results test the monitoring mechanisms in the law. And context tests the integration of the new legislation within the existing system of laws. The value of the test lies in its originality as the first test of effectiveness, and its innovative concretization of effectiveness. The test is an excellent tool in scrutinizing legislation and is envisaged to be used along with the existing toolkit of legislative evaluation.

The question is, whether the fragmentation of legislative evaluation to sub-exercises by the various actors on their own task in the regulatory effort maintains the existing fragmented image of scrutiny. The effectiveness test, impact assessments, cost benefit analyses are excellent in assessing fragments of the mosaic that is legislation and regulation. And they serve their individual fragmented purpose very well indeed. But legislation is not fragmented and neither is regulation. An enlightened pre and post legislative scrutiny exercise can and must bring all those elements together in a holistic summary evaluation that enhances the unique interrelation and interdependence of efficacy, effectiveness and cost-efficiency.

Such an enlightened scrutiny exercise would start by identifying the original regulatory goals. Here the input of policy officers is crucial, and their open disclosure of the real policy aims absolutely necessary. The problem is that, in practice, especially in legislatively immature jurisdictions, legislation is passed as a response to the Ministerial request. Often this excludes policy analyses that study the social phenomenon targeted, the relationship between the phenomenon and its causal roots, the comparative evaluation of possible regulatory option and their cost-efficiency, and the basis on which the decision to legislate has been taken. A pre or

\footnotetext{
${ }^{19}$ M. Mousmouti, 'Operationalising Quality of Legislation through the Effectiveness Test' (2012), 6:2 Legisprudence 201.
} 
post-legislative scrutiny exercise evaluating possible or post-facto effectiveness of the legislation cannot be without an understanding of what were the regulatory aims and the regulatory choices. ${ }^{20}$ Regulatory aims must be concrete enough to be achievable by legislation. For example, banning weapons as a means of achieving world peace or introducing a new benefit as a means of eradicating poverty may sound as wonderful goals but they are unobtainable by legislative means, and any legislative text will end up being ineffective. Is this such a bad thing? Apart from setting out to fail, a government that consciously decide to proceed with such legislation conveys to citizens the fraudulent impression that measures to address a social phenomenon are taken, whereas in reality what is undertaken is a useless exercise that will bear no effect to the phenomenon. Banning weapons cannot enhance world peace as violence and wars will carry on with current or illegal weapons; similarly, a new benefit cannot eradicate poverty, at least not outside the concrete circle of beneficiaries and even those at a limited extent. What banning weapons can do is reduce the number of weapons in the jurisdiction by, say $50 \%$ within a period of one year; reveal and control those licensed to carry weapons; and reduce the number of violence involving weapons in the jurisdiction by, say $30 \%$ within a five year period. Similarly, a new benefit can reduce the number of citizens living under the poverty line by, say $10 \%$ within the first year. Of course, the percentages and periods above would be set based on the pre-legislative studies undertaken at the regulatory policy stage.

Once the regulatory goals are identified, measuring effectiveness becomes a rather concrete task. Has efficacy been achieved? If the regulatory results have been produced, the capacity of the legislative text to contribute to the regulatory effort is proven. If the results are not there, the social scientists participating in the scrutiny exercise need to identify the error. If the error lies with the choice of the regulatory mechanism, then alternative means of regulation can be sought and the legislation can be repealed; or the legislation can be supported by additional regulatory mechanisms. If the problem lies with the content of the legislation, the substantive lawyers must investigate the effects of the legislation to the legal system, and identify the continuing mischief. The mischief can be a result of a legal or drafting error. If the legal system corrected itself in response to the legislation, the lawyers must identify how this occurred and how to prevent it from happening. For example, if weapons were banned but

\footnotetext{
${ }^{20}$ M. Zamboni, "Legislative Policy and effectiveness: a (small) contribution from legal theory" (2018) European Journal of Risk Regulation p.6 eloquently asks "effective in relation to what?".
} 
knives were not, then the concept of the substantive law needs to be extended to knives also. If the benefit was introduced but it competes with another benefit somewhere else in the social welfare system that is preferred by the users, then the conflict between the two benefits needs resolving. If all of the above check out fine, then, and only then, is editing of the text attempted.

Although this reads as a logical sequence of scrutiny tests, in practice, legislative scrutiny is still restricted to the editing of the words of the texts, both at the pre and the postlegislative scrutiny exercises. Removing the exclusive correlation of editing to scrutiny of legislation can be the greatest innovation in the assessment of legislation, especially at the prelegislative stage. This often calcified ethos, highly frequent in Ministries in the Commonwealth, reduces scrutiny to an English language check and deprives the jurisdiction from the opportunity to reconnect the links of the chain that is the drafting process as part of the legislative process as part of the policy process.

Effectiveness is not about words, and neither is drafting and scrutinising legislation. At a pre-legislative scrutiny exercise, effectiveness demands answers to the following tests, all contributing to an answer to the question whether the legislative text is capable of producing the desired regulatory results:

1. Testing the conceptual effectiveness of the regulatory concept

a. Which are the desired regulatory results?

b. How can they be measured?

c. Within how long are they to be achieved?

d. Can the selected enforcement mechanisms produce the desired regulatory results within the set times?

e. Can the text be implemented without stumbling on socio-legal hurdles?

2. Testing the effectiveness of the legislative concept

a. What is the legal mischief and how is it connected to the desired regulatory goals?

b. Is this addressed by non-legislative means in the jurisdiction?

c. How is the new legislation expected to address the mischief?

3. Testing the effectiveness of the legislative communication

a. Which are the main groups of possible users of the text?

b. What level of awareness of the topic do they have?

c. What is their level of legal awareness? 
d. What questions does each group ask?

e. Does the current structure provide accessible answers the specific questions of each of the user groups?

f. Does the current structure facilitate the unhindered identification of the relevant answers?

4. Testing the effectiveness of legislative expression

a. Does the language of each provision communicate its message to each of the intended user groups in a manner that they can understand (topic and law)?

b. If this is difficult, what tools have been used to address complexity?

i. Examples

ii. Definitions or interpretation

5. Testing the effectiveness of presentation

a. Is the layout simple?

b. Does the text refer the user to relevant provisions, perhaps via:

i. Hyperlinks

ii. Explanatory notes

6. Testing the effectiveness of monitoring

a. How often

b. With which results?

The elements of this effectiveness test function consecutively. It is a concept of "sudden death": if the text fails one test, it fails automatically the ones below. In a pre-legislative scrutiny exercise, failure in one test puts a stop to the exercise, and is evidence of ineffectiveness of the text.

This new effectiveness test differs from others preceding it on two grounds. First, it is highly individualised and requires in depth analysis of policy, law, and legislation. It is not fertile for box ticking scrutiny exercises. Second, it can only be performed adequately with the participation of the whole Bill team, including policy officers, legal officers, drafters, and practitioners: as such it conforms with Sir Stephen Laws' holistic depiction of effectiveness as a concept that brings together policy, law, and drafting. ${ }^{21}$ It does not substitute existing scrutiny

\footnotetext{
${ }^{21}$ Sir Stephen Laws, "Legislation and Politics" in D. Feldman, Law in Politics, Politics and Law (2013, Hart Publishers, Oxford), p.90.
} 
exercises, it synthesises them and gives them context and meaning by means of a holistic review of legislation as a means of regulation.

It does not differ enormously from Mousmouti's test but it adds more elements to it, also looking at the legislative expression and layout. In doing so it reflects the current trends of easification and identification of the precise audiences of the legislative text. And the test conforms with Zamboni's theory of three pillars of effectiveness, ideal, situation, results, ${ }^{22}$ in that it encompasses policy ideals, socio-cultural-economic-political-legal parameters of the legislative environment, and internal and external results (change in the law and in behaviour).

At a post-legislative scrutiny exercise, effectiveness demands answers to the following questions in a consecutive order:

1. Which were the desired regulatory results pursued by means of the legislation?

2. Has the selected regulatory mechanisms led to the desired regulatory results, as evidenced by empirical data ${ }^{23}$ ?

3. Has the legal mischief been addressed by new legislation, as evidenced by data ${ }^{24}$ ?

4. Were there any issues arising from the choice of legislative expression and how can these be addressed?

5. Is efficacy achieved?

6. If not, was the legislation effective as evidenced by 3 and 4 ?

7. If not, how can the issues be addressed: repeal, repeal and re-enact, amend the legislation?

8. In how many years does the legislation need to be re-evaluated?

Answering these questions require an inter-disciplinary team representing all actors in the regulatory process and making use of all toolkits of legislative scrutiny. It could serve as the internal and external evaluation stage of Thornton's stages of the drafting process. It could take place as the final meeting of the Bill team at the pre-legislative stage. IT could produce a brief executive pre-legislative report that could be fed to Parliament, thus facilitating the meaty

\footnotetext{
${ }^{22}$ M.Zamboni, op.cit., pp.6-7.

${ }^{23}$ O. D. Oliver-Lalana 'Due Post-Legislative Process? On the Lawmakers' Constitutional Duties of Monitoring and Revision in K. Messerschimdt \& A. D. Oliver-Lalana (Eds) Rational Lawmaking under Review. Legisprudence According to the German Federal Constitutional Court (Springer 2016) 259.

24 J. Rachlinski ‘Evidence-Based Law’ (2011) 96 Cornell Law Review 901-923, 910.
} 
scrutiny of legislation by legislators. And it could be used as the starting point for postlemgislative scrutiny.

Could it also be fed into the legislative text, thus binding future post-legislative scrutiny exercises to the use of agreed concrete quality tests for the particular legislation?

\section{E. A new genre of purpose/objectives clauses as the application of effectiveness to legislative scrutiny ${ }^{25}$}

It is conceivable that the text of legislation could be used for that purpose. ${ }^{26}$ And it already has the type of provision that is perfect for the job.

Purpose clauses express what purpose or objectives the legislative text pursues, and reflect the general ethos of legislative intent. ${ }^{27}$ They are considered as tools offering the user an insight of the reasoning of regulators, thus enhancing comprehension ${ }^{28}$. They can be 'perfect topic specifiers ${ }^{29}$. They can state what the statute intends to achieve. ${ }^{30}$ And so they are perfect for stating the desired regulatory results and serving as pronouncements of future success.

It is precisely this fluidity in their nature that has led purpose clauses treacherous paths. ${ }^{31}$ Purpose clauses are operative provisions of the Act, and they must be expressed in clear, precise, and unambiguous terms. They are to be drafted using the same precise and concise terms used elsewhere in legislation, and must focus on the results intended to be achieved rather than the means of achieving them. An example of good practice would state:

\footnotetext{
${ }^{25}$ H. Xanthaki, Drafting Legislation: Art and Technology of Rules for Regulation (2014, Hart Publishers, Oxford), pp.185-188.

${ }^{26}$ D Berry 'Purpose Sections: Why They are a Good Idea for Drafters and Users' (2011) 2 The Loophole 49.

${ }^{27}$ B Drummond and P Marwood 'Purposive Drafting in Finance Bill 2007' (2007) 4 BTR 350, 354.

${ }^{28} \mathrm{~J}$ D Bransford and M K Johnson 'Contextual Prerequisites for Understanding: Some Investigations of Comprehension and Recall' (1972) 11 Journal of Verbal Learning and Verbal Behaviour 717; also L M S Miller, J A Cohen, and A Wingfield 'Contextual Knowledge Reduces Demands on Working Memory During Reading' (2006) 34 Memory Cognition 1355.

${ }^{29}$ I M L Turnbull 'Clear Legislative Drafting: New Approaches in Australia' (1990) 11 Statute Law Review 161, 169.

${ }^{30}$ Lord Renton 'Interpretation of Legislation' (1982) Statute Law Review 7, 10.

${ }^{31}$ D Greenberg, Craies on Legislation: A Practitioner's Guide to the Nature, Process, Effect and Interpretation of Legislation (9th edn, London, Sweet and Maxwell, 2008) 352; also the detailed expose of J Barnes 'Statutory Objects Provisions: How Cogent is the Research and Commentary?' (2012) 34 Statute Law Review12.
} 
The objectives of this Act are -

(a) to reduce the number of drivers with alcohol present in their blood when driving by $25 \%$ within a period of five years; and

(b) to reduce the number of car accidents caused by these drivers by $50 \%$ in the same period.

Unfortunately purpose or objectives provisions have in the past been usurped by expressions of emotive political statement that should not have found its way to the legislative text. ${ }^{32}$ In effect, they have been known to have been used instead of the now abolished preambles. An example of bad practice would state:

The purpose of this Act is -

(a) to curb the menace drunken drivers cause to themselves and to innocent drivers, passengers and pedestrians;

(b) to reduce the carnage on the roads caused by such drivers;

(c) to save lives.

There is no doubt that the second provision has no place in modern legislation. And has led to the ridicule and elimination of purpose clauses from modern legislative texts. But, within the context of using legislation as a means of regulation one wonders whether objectives provisions can set out in clear terms the tangible regulatory aims of the legislative text and the tangible measurable and concrete criteria by which these aims are to be achieved. If this were the case, objectives clauses would be directly linked to post legislative scrutiny, as they would offer the policy officers of the instructing department the opportunity to articulate the concrete regulatory results desired and to then apply those in the planned post legislative scrutiny

\footnotetext{
32 Office of the Scottish Parliamentary Counsel, Plain Language and Legislation, 2006), http://www.scotland.gov.uk/Publications/2006/02/17093804/0, 40.
} 
exercise for the purposes of assessing the effectiveness of the legislative text. ${ }^{33}$ All this with enhanced transparency as this would be in the public sphere. ${ }^{34}$

But, most importantly, this exercise would contribute to a closure of the current gap between legislative intent and legislative effect. ${ }^{35}$ In other words, in the drafting instructions clients would have to list what they hope to achieve by means of legislation, the drafter would have the opportunity to ascertain or reject legislation as a means of achieving the set regulatory results, the drafter would then incorporate the regulatory results in the legislation thus offering the Parliament an insight into what is required, how it is hoped that this will be produced, and on what basis the assessment of the success of the legislative text will take place at the post legislative stage. Parliament could then use the criteria of assessment to evaluate the quality of the post legislative exercise as a means of exercising meaningful parliamentary scrutiny, and then decide if the legislation can continue its life or whether it is has proven so inappropriate for the desired regulatory results that it should die and be deleted from the statute book. Here an end clause, known as 'duration' or 'sunset' clause could have the desired persuasive and empowerment effect. And so, a new mission for objectives provisions can offer them an unparalleled significance: their use as vessels of quality control of the whole regulatory cycle, from policy concept and formulation to legislative enactment and post legislative scrutiny.

But of course to achieve in this new role objectives clauses must be drafted in concrete terms, and the criteria used must be deprived of political nuances and introduced as a matter of fact measures of scrutiny. There is little doubt that this requires a significant change in the ethos of drafting objectives clauses. But the elements of that are already here: presumably identifying measures of quality for post legislative scrutiny apply the same ethos of concreteness and precision. And so what would be required really would be the incorporation of post legislative scrutiny elements into the pre-legislative drafting process.

\section{Concluding remarks}

\footnotetext{
${ }^{33}$ On the sunsetting policy, http://www.bis.gov.uk/policies/better-regulation/better-regulationexecutive/reducing-regulation-made-simple.

${ }^{34}$ M Malik 'From Conflict to Cohesion: Competing Interests in Equality Law and Policy' (2009) 187 Equal Opportunity Review 11, 12-13.

${ }^{35}$ E R Beerworth 'The Evaluation of Legislation' in R Tomasic (ed), Legislation and Society in Australia (Allen and Unwin, 1980) 66, 68.
} 
The aim of this paper was to introduce an enlightened approach to legislative scrutiny, with effectiveness at the epicentre of the exercise. Effectiveness is now prevalent as the conceptual criterion for legislative quality. However, it has only been applied to the drafting rather than the scrutiny of legislation.

One of the main reasons behind this is the perception that effectiveness is somehow theoretical, abstract and therefore application-unfriendly. This cannot be further from the truth. Effectiveness encompasses both a theoretical and a practical aspect, and can therefore easily apply to theoretical and practical legislative dilemmas.

What is fair to state, however, is that effectiveness is fluid and relative, mainly because it inevitably draws its conceptual referents from the individualised elements of the legislation to which it refers, but also from the characteristics of the political, cultural, religious and legislative environments within which it operates. This fluidity and relativity is far from a negative attribute of effectiveness. It is both justified and positive. It is justified because it derives from the nature of legislation as phronetic. And it is positive because it allows effectiveness to take a particular guise by reference to the particular legislative text to which it is attached. And this is exactly how it becomes concrete enough to serve in legislative scrutiny.

Individualised as it must be, however, effectiveness carries essential and universal conceptual referents. These were identified in the 6-element effectiveness test forming the content of enlightened pre- and post-legislative scrutiny exercises. These refer to the viewing of legislation as a tool for regulation, and the consequent linkage of legislative to policy scrutiny. Effectiveness is defined as the capacity of the text to contribute to the attainment of the desired regulatory results. Legislation cannot be scrutinised in a vacuum. The desired regulatory results need to become known so that any legislative effect is juxtaposed to them. The legal environment pre and post the new legislative text must also be juxtaposed to demonstrate the effect of legislation to the legal status quo. And, of course, drafting choices must be revisited to assess if and how a contribution to policy and law has indeed been made.

A positive assessment signifies an effective law, which can be kept in the statute book for an additional period of time (remember, effectiveness is time fluid too so regular assessments are necessary, notwithstanding the successful completion of the previous scrutiny exercise). A partially positive assessment invites for further research in the roots of the partial ineffectiveness, and further agreement, based on empirical data, on the way forward. Possible choices are maintenance of the text to allow it time to produce results, fine-tuning of the text 
to address ineffective aspects, or repeal and re-enactment of a new text based on new regulatory choices. A negative assessment invites for study into the causes of ineffectiveness: at what point is there an error, the policy, the law, or the drafting. Empirical and qualitative analysis of the social phenomenon, its roots, and the social/cultural/religious/legal environment of the jurisdiction where it text functioned can pinpoint the problem. And this can lead to similar choices as an assessment of partial effectiveness.

This type of scrutiny exercise, especially since it requires study of the individualised referents of effectiveness, can only be complete as an inter-disciplinary effort.

It also requires a holistic scrutiny exercise that summarises and utilises all current scrutiny tools, such as impact assessment, cost benefit analysis etc.

It is not easy to be thrilled at the prospect of another layer of bureaucracy in the current heavily regulated process of law making. But this is far from a bureaucratic exercise: it invites a ties-off, jackets-off, coffeed-up think-tank of scientists representing all actors in the policy process working together without hierarchical constraints to produce a true image of the effect of legislation as a tool of regulation. Moreover, this is not a useless exercise. It can produce a short executive report of its findings that can inform Parliament, and the legislative audiences on the objective, content, legal effect, and desired or achieved results of the legislative text. It can inspire endorsement and implementation. It can clarify enforcement parameters. And, most importantly for legislative scientists, it finally ties the now fragmented loose ends of the legislative process.

Furthermore, it can lead to the drafting of purpose/objectives clauses that express the individualised, tangible, and measurable criteria of effectiveness of the particular text, thus ensuring that post-legislative scrutiny is, finally, undertaken in the depth and extent that the production of good legislation demands. With real effectiveness at the epicentre. 